\title{
Nano Plasma Technology Production for Tiles Against Piercing Weaponry
}

\author{
Baruch B. Gutman*
}

\section{USSR Israel - St. Francis College, New York, USA}

\begin{abstract}
In light of the vital important problem of protecting the lives of military people against piercing weaponry Nano scale atomization plasma technology was developed to produce the tiles with highest micro hardness from metalceramics many layers materials. Inside a DC generator of plasma jet are propagated a number of shock waves being created by pulses with a certain frequency range and slope of a front of each within $10^{9} \mathrm{~A} / \mathrm{s}$.

High enthalpy plasma generation is realized through a proprietary DC modulation scheme and the special torch head design that combines oxy-fuel and plasma arc processes. The Shock Waves Atomization Plasma Technology allows controlling the size of spray particles on their way to a target surface preventing any defects in thick tile's body. Traditional DC plasma torches are very costly for long term use (what is absolutely necessary for thick like tiles materials) the expensive helium/argon/nitrogen/hydrogen mixtures. Beside that, the existing spraying technologies are limited in terms of deposition efficiency, quality of coating, coating micro hardness, porosity and density.

The advantages of this technology are very impressive: micro hardness of Metal - Ceramic tiles (Alumina) may reach $2,500 \mathrm{HV}$ and can be increased to double (it will be described almost double in a next article, for alumina-titanium powder in air- hydrocarbon plasma mixture, etc.)

Low level of operation costs, upon highest deposition efficiency (90\%), opens the way to get the tiles with greatest thickness: $10 \mathrm{~mm}, 20 \mathrm{~mm}$ and so on without any cracks under low operating expenses.
\end{abstract}

\section{INTRODUCTION}

In accordance with the major goal: to develop the multilayers Metal -Ceramics tiles to protect a military vehicles against piercing weaponry, Nano Scale Plasma Atomization Technology [1-4] produced a number of types of samples having the size $20 \mathrm{x} 40 \mathrm{~mm}$ and a thickness variable over the range of $10-25 \mathrm{~mm}$. It should be noted that the regular thickness of the plasma sprayed coating is within $100-300 \mu \mathrm{m}$.

According to the technological operation mode results these samples have included 5 layers generated by the shock waves plasma spraying method for alumina and $\mathrm{NiAl}$ (Metco 450).

Metallographic sections were prepared for all types of the samples and examined by SEM (scanning electron microscopy) in order to determine their structural characteristics and by EDS (energy dispersion spectroscopy) and specifying a composition along the layers.

The micro-hardness of the layers was also measured by the standard ASTM E 384 with Vickers Indenter under load 200 gram together with Rockwell method $(\mathrm{N}-30 \mathrm{~kg})$ and transformed to Vickers units.

A number of the samples were exposed to X-Ray diffraction (XRD).

\section{EXPERIMENTAL RESULTS FOR SAMPLE NO 1}

The alumina layer contained a certain concentration of $\mathrm{ZrO}_{2}$ (Zirconium oxide was added to prevent cracking) and

*Address correspondence to this author at the USSR Israel - St. Francis College, New York, USA; Tel: 346-247-9930;

E-mail: boris649@yahoo.com this is probably one from a number of reasons for the low hardness of the layer, which is less than half own hardness of the aluminum oxide.

The sodium in a low concentration was found as well.

In the rest of the layers the grade of the composition was not preserved (for example the second layer is richer by metal than third layer).

The thickness of layers was not the same, and this difference is clearly demonstrated at Fig. (1).

Result of X-ray diffraction shows that the concentration of Zirconium oxide is comparatively higher for a ceramic layer but additional phases could not be identified (Fig. 2).

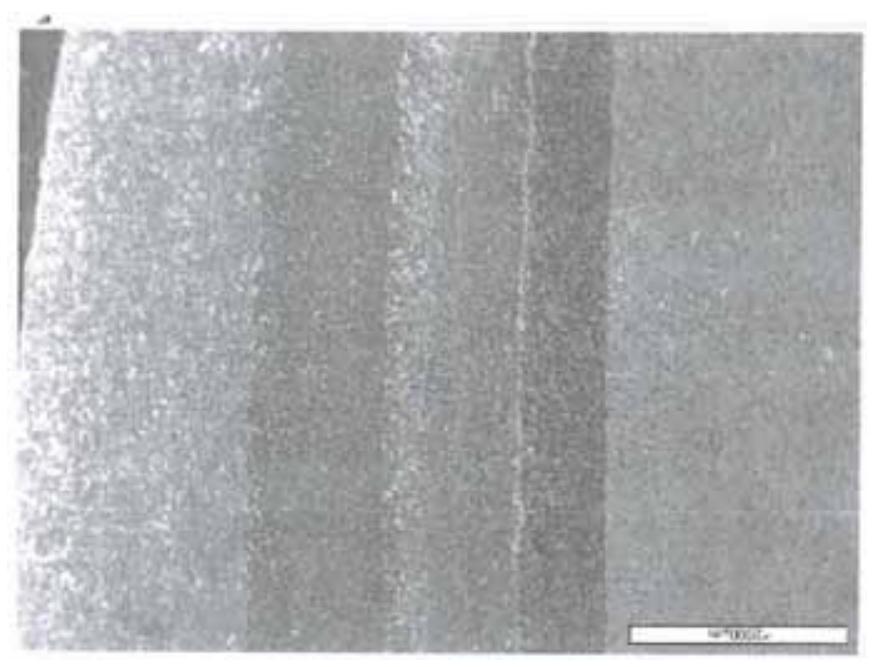

Fig. (1). General view of the cross section shown for sample $\# 1$ (thickness is $\sim 2,000 \mu \mathrm{m}$ ). 


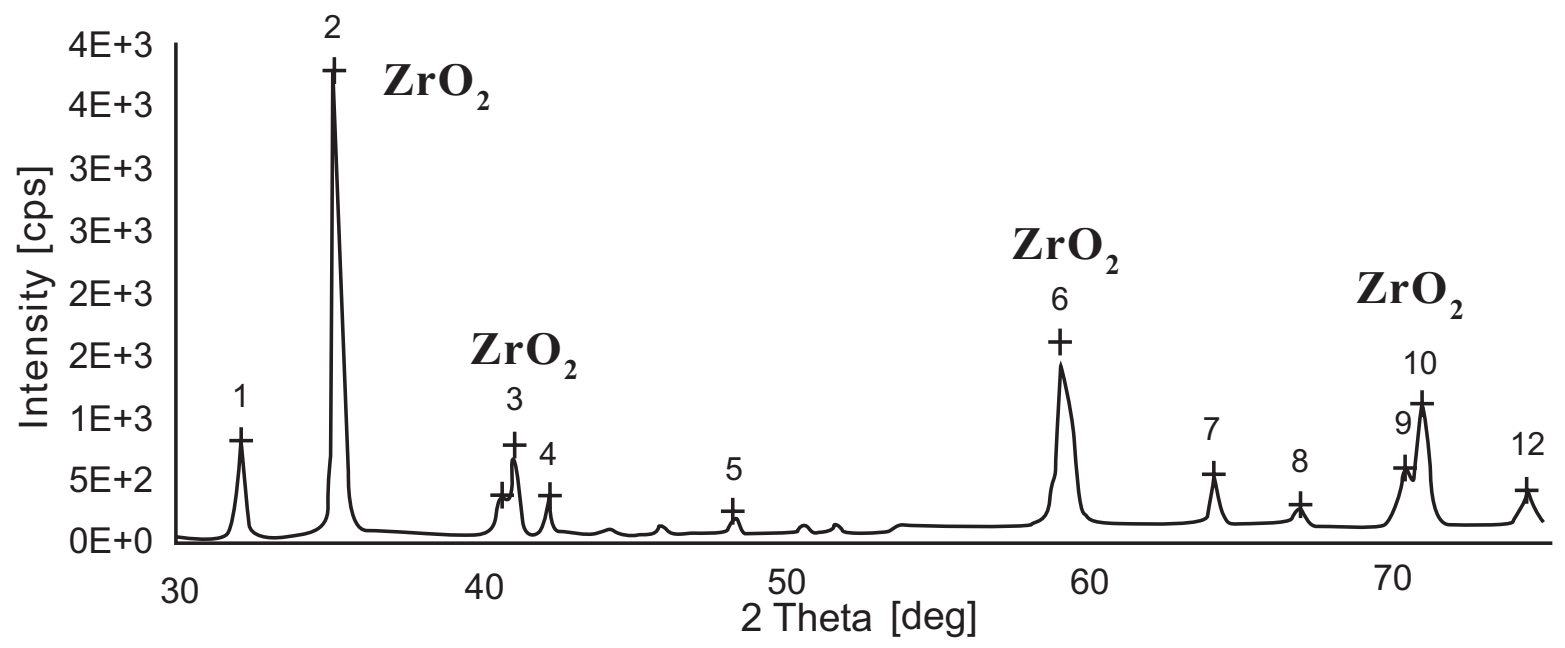

Fig. (2). Results of X-ray analyses of the ceramic layer shown in sample \#1.

Chemical composition of the layers (EDS analyses) of the sample \#1versus micro - hardness shown in the Table 1.

Let's consider the microstructures of each layer:

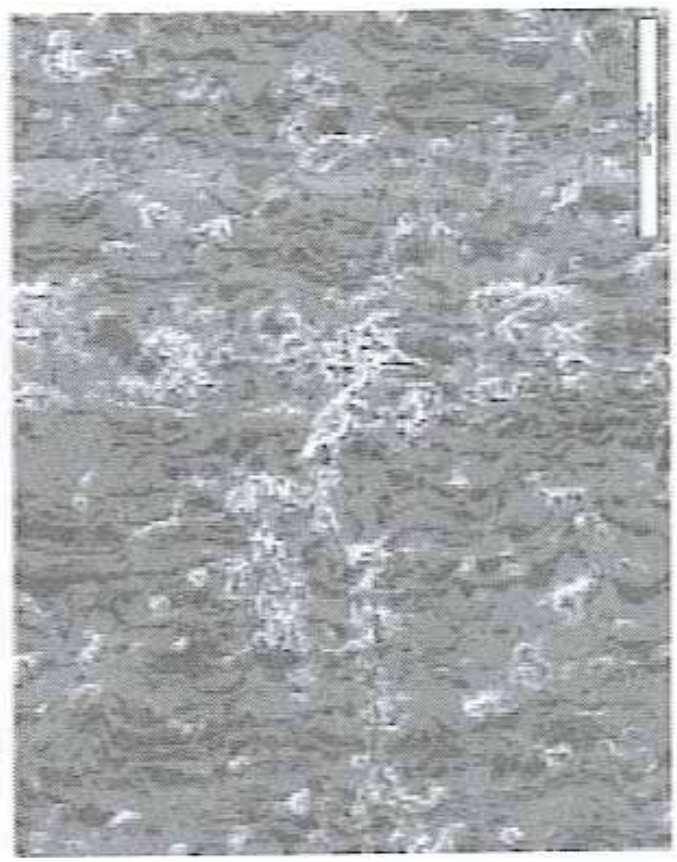

Fig. (3). The structure of the first layer ("rich" in aluminum oxide) shows for the sample \# 1 (dark phase: alumina, light phase: zirconium oxide), $\mathrm{x} 200$.

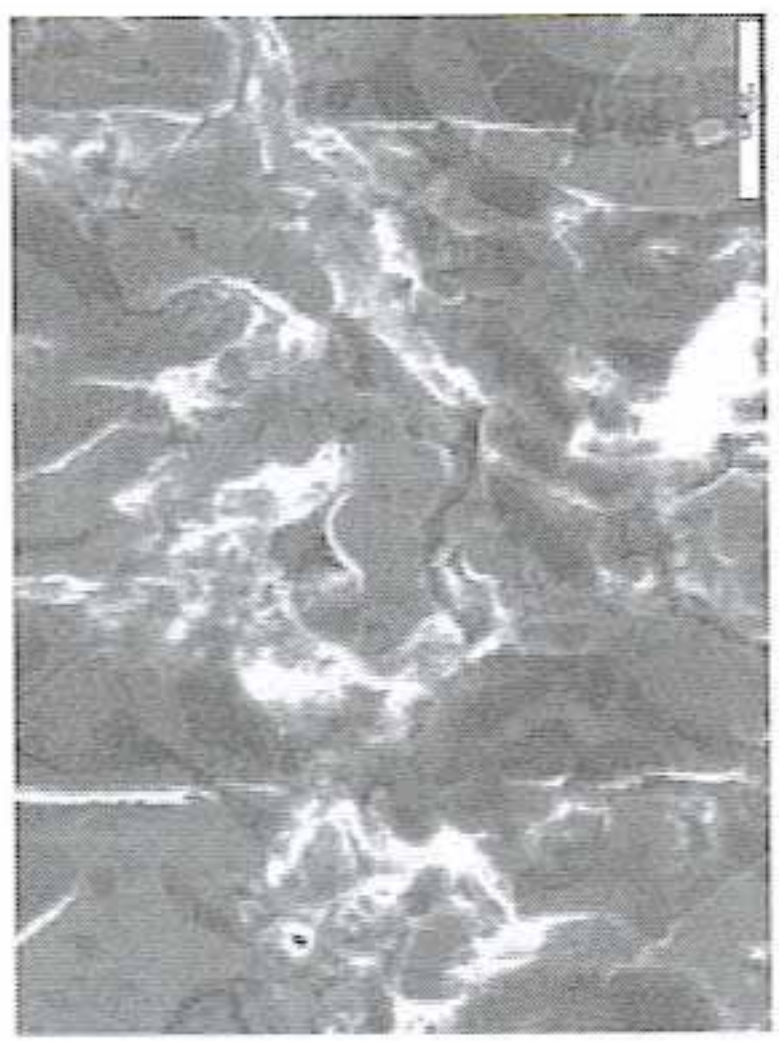

Fig. (4). The structure of the first layer shown for sample \# 1, $\mathrm{x} 1000$.

Table 1. Components and Micro - Hardness of Layers

\begin{tabular}{|c|c|c|c|c|c|}
\hline $\mathbf{5}$ & $\mathbf{4}$ & $\mathbf{3}$ & $\mathbf{2}$ & $\mathbf{1}$ & Layers No. \\
\hline \hline $18 \% \mathrm{Al}_{2} \mathrm{O}_{3}$ & $14 \% \mathrm{Al}_{2} \mathrm{O}_{3}$ & $63 \% \mathrm{Al}_{2} \mathrm{O}_{3}$ & $50 \% \mathrm{Al}_{2} \mathrm{O}_{3}$ & $25 \% \mathrm{Al}_{2} \mathrm{O}_{3}$ & $\%$ measured \\
\hline $11 \% \mathrm{Al}$ & $8 \% \mathrm{Al}$ & $25 \% \mathrm{Al}$ & $23 \% \mathrm{Al}$ & $74 \% \mathrm{Al}$ & $\%$ measured \\
\hline $70 \% \mathrm{Ni}$ & $50 \% \mathrm{Ni}$ & $12 \% \mathrm{Ni}$ & $27 \% \mathrm{Ni}$ & & $\%$ measured \\
\hline & $28 \% \mathrm{Zr}$ & & & 650 & Micro-hardness HV-30 kg \\
\hline
\end{tabular}




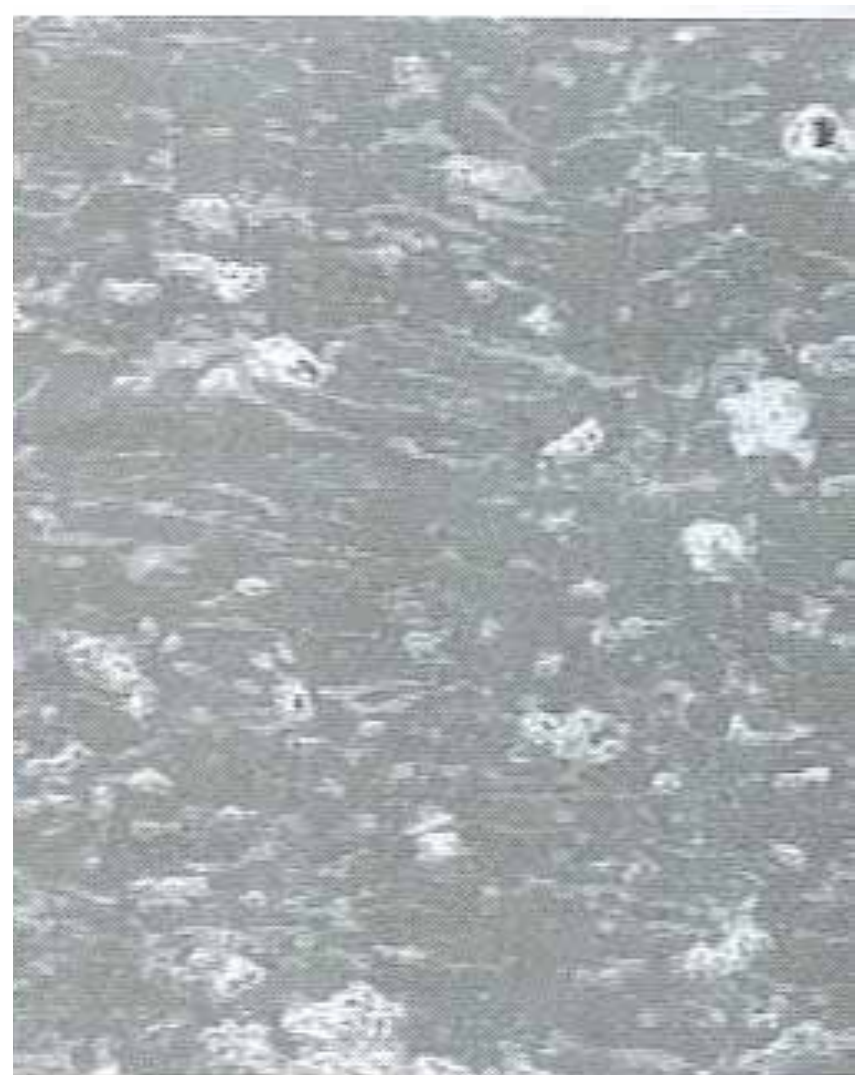

Fig. (5). The structure of the second layer shown for sample \# 1(dark phase: alumina-aluminum oxide, light phase: nickel), x200.

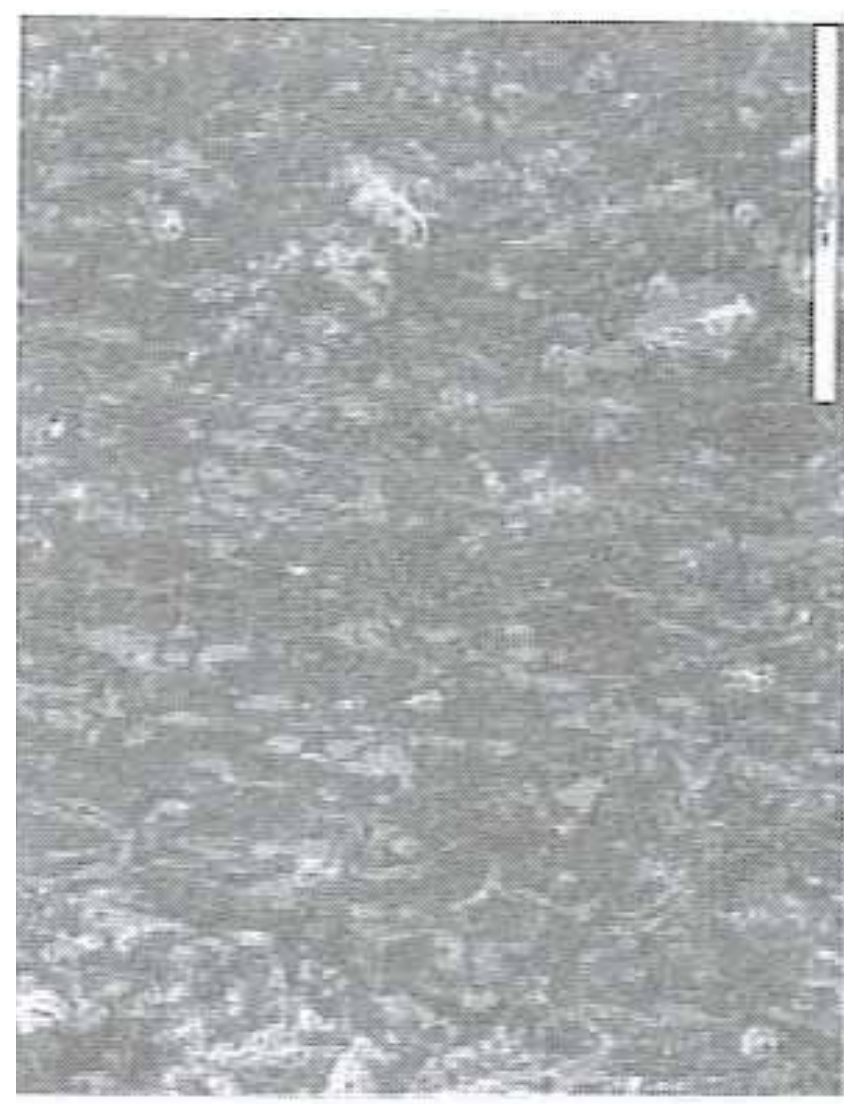

Fig. (6). The structure of the third layer shown for sample \# 1, x200.

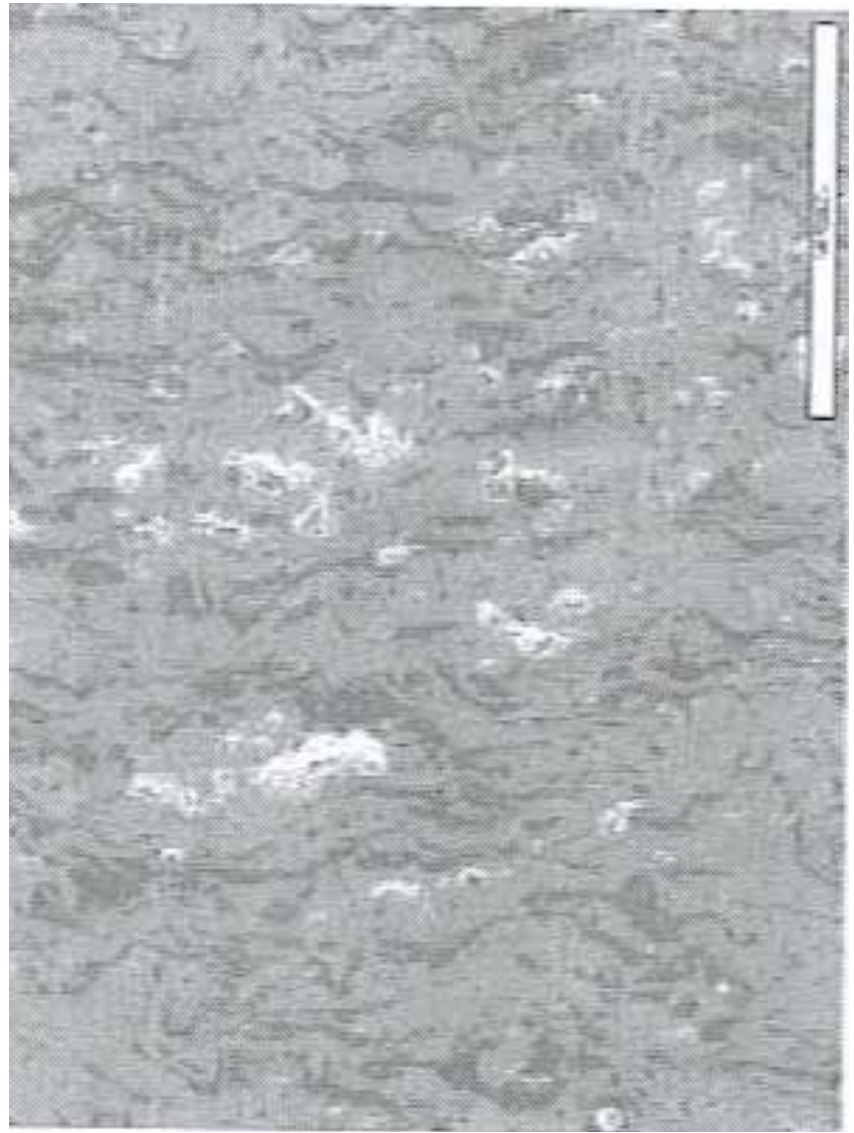

Fig. (7). The structure of the fourth layer shown for sample \#1, $\mathrm{x} 200$.

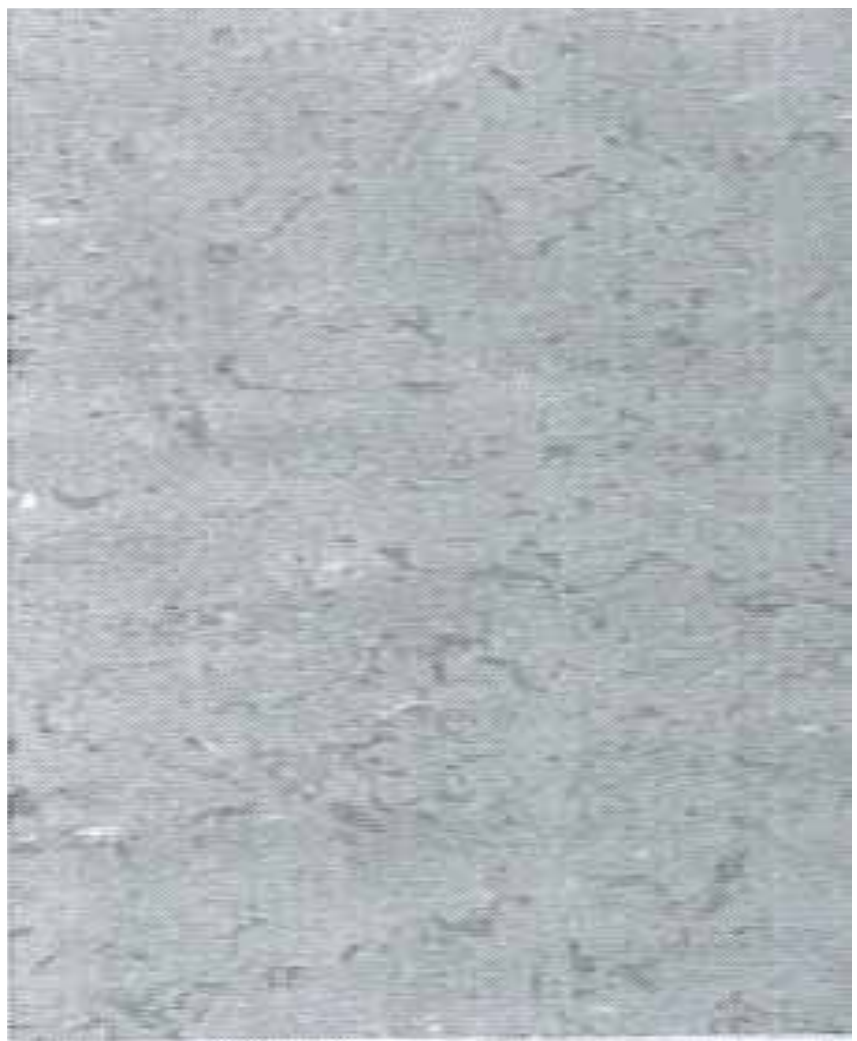

Fig. (8). The structure of the fifth layer shown for sample \# 1(Ni is the main component), $\mathrm{x} 200$. 


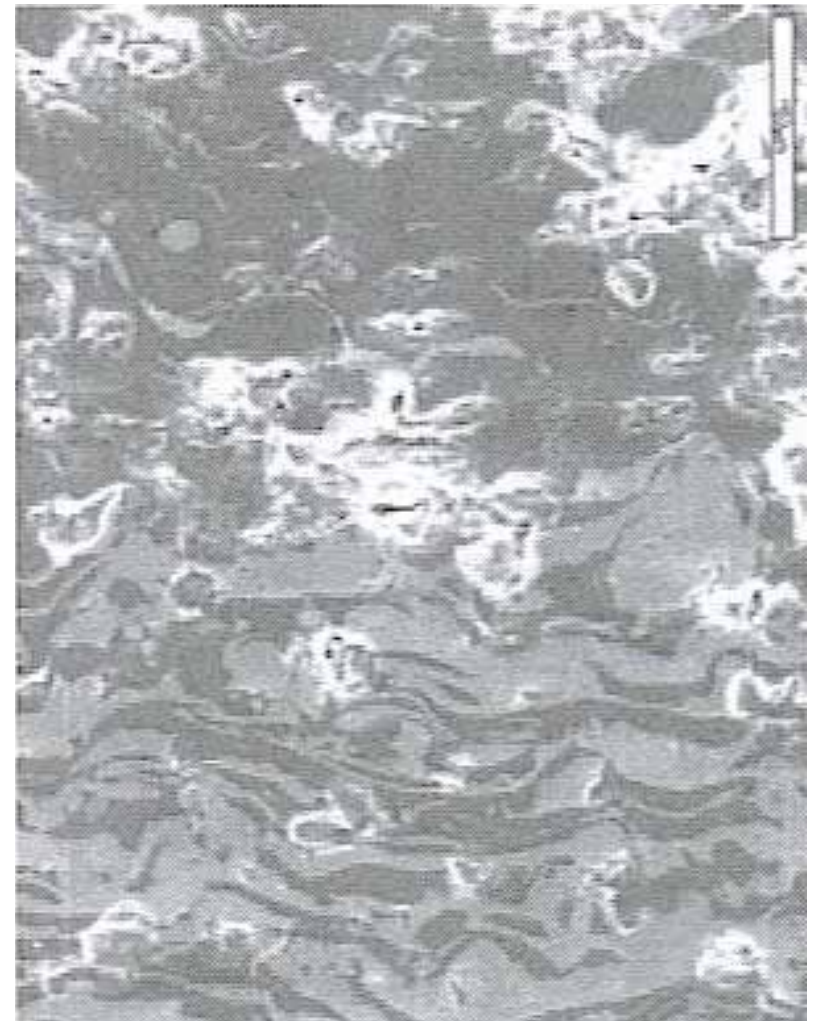

Fig. (9). An area of a connection between the first and second layers shown for sample \#1, x500.

Figs. (2-9) describes the representative structure of each layer in sample \# 1 . The layers \# 2 and \# 3 include relatively low concentration of nickel + aluminum oxide and / or alumina (there is difficulty in describing by the EDS method between aluminum oxide and alumina), while in layers \# 4 and 5 there is noticeable growth of the concentration of the metals (nickel + aluminum oxide) which become the main component (about $80 \%$ in layer \# 5).

The interface area between the layers in the majority of cases looks normal, without any special defects (Fig. 9).

\section{Experimental Results for Sample No 2.}

This sample was prepared in the inverse order from the previous one, where the metal layer was a first one.

Among the three last layers there are separations between the layers and a crack that crosses them perpendicularly (Fig. 10).

The composition of the layers is partially similar to sample \# 1.

The zirconium oxide in the last layer was discovered in notable concentration (Fig. 11).

The composition of the first layer is just NiAl intermetallic powder (Fig. 12, Table 2).

In the ceramic layer the high local hardness $(1250 \mathrm{HV})$ is discovered, which approximates the hardness of aluminum oxide, but this does not characterize the hardness of the layer which corresponds to about half of this hardness.

The gradient of the hardness does not approximate the expected one (military alumina tile is produced by the

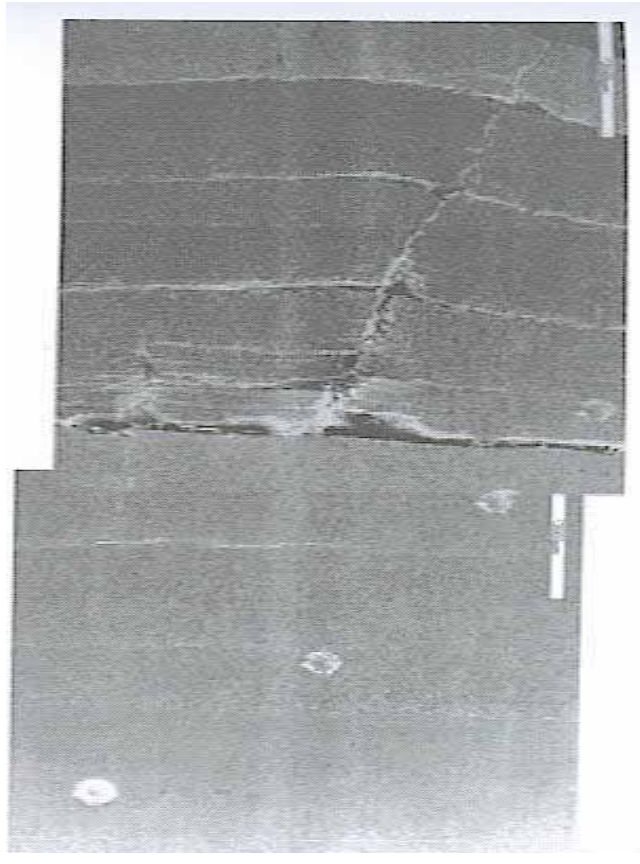

Fig. (10). The cross section of sample \# 2: there are parallel and perpendicular cracks of layers \# 4 and \# 5 and the light circles are the traces of hardness measurements: $x 15$.

pressure- thermal sintering of aluminum oxide powder under temperature $\sim 1,700^{\circ} \mathrm{C}$ has a micro-hardness within $\sim 1,500$ HV) $[5,6]$.

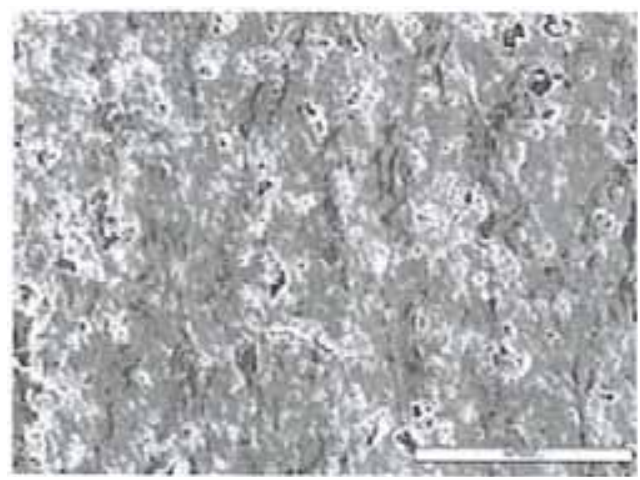

Fig. (11). Microstructure of sample \# 2 shows in the figure (the fifth ceramic layer enriched by zirconium oxide), x200.

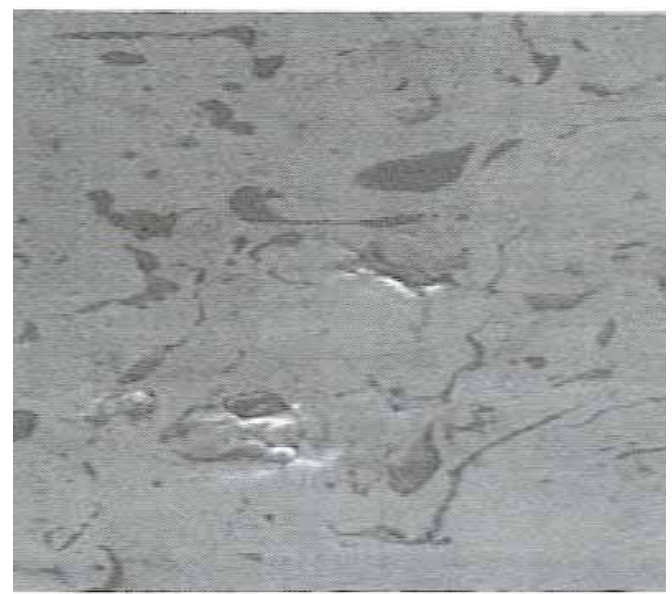

Fig. (12). The first layer shown for sample 2 (the light phase is $\mathrm{Ni}$, and the dark phase is $\mathrm{Al}), \mathrm{x} 200$. 
Table 2. The List of the Components Versus a Micro-Hardness of the Layers Shows for Sample No 2

\begin{tabular}{|c|c|c|c|c|c|}
\hline $\mathbf{5}$ & $\mathbf{4}$ & $\mathbf{3}$ & $\mathbf{2}$ & $\mathbf{1}$ & Layers, No. \\
\hline \hline $10 \% \mathrm{Al}_{2} \mathrm{O}_{3}$ & $64 \% \mathrm{Al}_{2} \mathrm{O}_{3}$ & $40 \% \mathrm{Al}_{2} \mathrm{O}_{3}$ & $25 \% \mathrm{Al}_{2} \mathrm{O}_{3}$ & $5 \% \mathrm{Al}_{2} \mathrm{O}_{3}$ & $\%$ measured \\
\hline $88 \% \mathrm{ZrO}_{2}$ & $22 \% \mathrm{Al}$ & $20 \% \mathrm{Al}$ & $13 \% \mathrm{Al}$ & $\%$ measured \\
\hline $2 \% \mathrm{Na}$ & $14 \% \mathrm{Ni}$ & $40 \% \mathrm{Ni}$ & $62 \% \mathrm{Ni}$ & $95 \% \mathrm{Ni}$ measured \\
\hline 650 & 545 & 580 & 580 & 435 & Micro-hardness HV-30 kg \\
\hline
\end{tabular}

\section{Experimental Results for Sample No 3}

$\mathrm{T}$ he list of a composition of the layers is given in Table $\mathbf{3}$ and results of X-Ray diffraction analyses in Fig. (13).
The level of the hardness is low as a rule (maximum hardness is usually $650-1200 \mathrm{HV}$ ) with the gradient of the hardness rising in direction of the ceramic layer in the majority of cases.

Table 3. The Results of Chemical Composition for Sample \# 3 Versus Micro-Hardness

\begin{tabular}{|c|c|c|c|c|c|}
\hline $\mathbf{5}$ & $\mathbf{4}$ & $\mathbf{3}$ & $\mathbf{2}$ & $\mathbf{1}$ & Layers, No. \\
\hline \hline $16 \% \mathrm{Al}_{2} \mathrm{O}_{3}$ & $47 \% \mathrm{Al}_{2} \mathrm{O}_{3}$ & $53 \% \mathrm{Al}_{2} \mathrm{O}_{3}$ & $84 \% \mathrm{Al}_{2} \mathrm{O}_{3}$ & $86 \% \mathrm{Al}_{2} \mathrm{O}_{3}$ & $\%$ measured \\
\hline & $8 \% \mathrm{Al}$ & $9 \% \mathrm{Al}$ & & & $\%$ measured \\
\hline & $5 \% \mathrm{ZrO}_{2}$ & $11 \% \mathrm{ZrO}_{2}$ & $15 \mathrm{ZrO} 2$ & $10 \% \mathrm{ZrO}_{2}$ & $\%$ measured \\
\hline $84 \% \mathrm{Ni}$ & $40 \% \mathrm{Ni}$ & $28 \% \mathrm{Ni}$ & $1 \% \mathrm{Ni}$ & $1 \% \mathrm{Na}, 2 \% \mathrm{Ni}$ & 620 \\
\hline 350 & 425 & 640 & 910 & Micro-hardness $\mathrm{HV}-30 \mathrm{~kg}$ \\
\hline
\end{tabular}

In the second layer a relatively high level of hardness is discovered, while in the first "ceramic" layer hardness is lower.

\section{Experimental Results for Sample No 4}

In this sample, the levels of the hardness are low with moderate gradient rising in the direction of the first "ceramic layer" (Table 4).

In the majority of the samples that were examined the layers structure with good bonding was determined as a rule except for sample \# 3.

The sample \# 2 that was prepared in the inverse order (the ceramic layer was the last one) includes cracks between the last layers and in the perpendicular direction as well.

\section{New Approach}

In order to substitute a sintering method, the new plasma technology method has been developed.

The flux of materials being sprayed and cooled down under the quenching speed $10^{5}-10^{6} \mathrm{~K} / \mathrm{s}$ in combination with DC arc modulation under frequency rate $\sim 30 \mathrm{kHz}$ to provide a generation of amorphous particles and a crystal lattice formation. Nano scale particles cooled down at the expense of a big surface corresponding to their small diameter during dwell time to the substrate, providing a highest microhardness as a result of amorphous particles formations [1].

In the classic method the heated up and cooled down process was carried out for several hours.

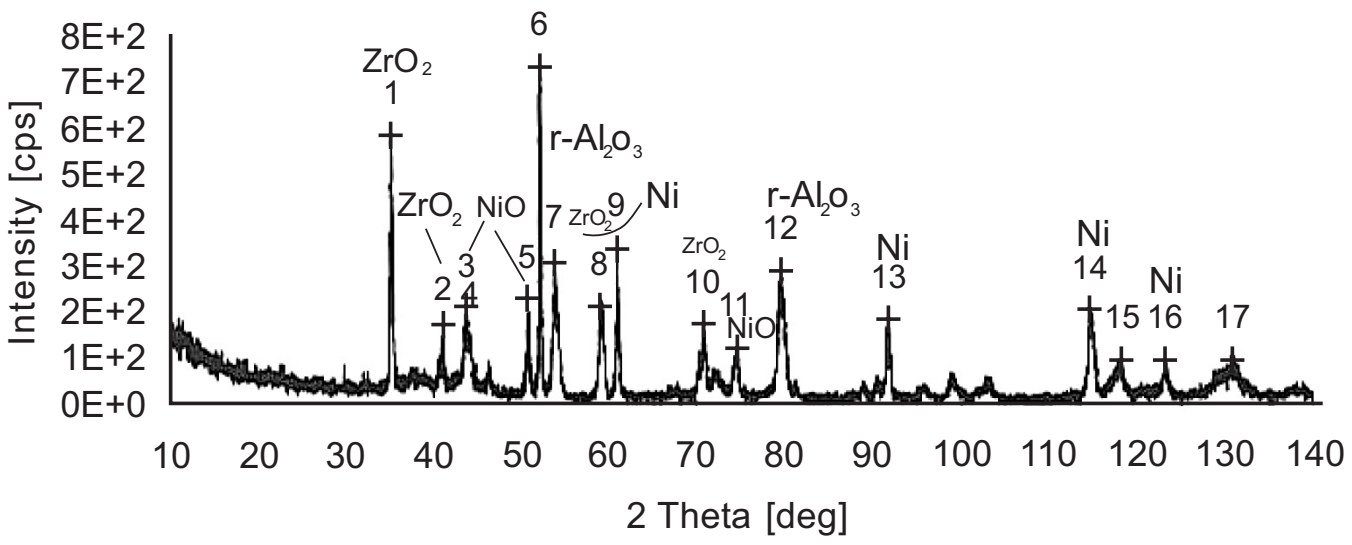

Fig. (13). X-Ray diffraction analyses results shown for first ceramic layer of sample \# 3 . 
Table 4. The Results of Chemical Composition for Sample \# 4 Versus Micro Hardness

\begin{tabular}{|c|c|c|c|c|c|}
\hline $\mathbf{5}$ & $\mathbf{4}$ & $\mathbf{3}$ & $\mathbf{2}$ & $\mathbf{1}$ & Layers, No. \\
\hline \hline $7 \% \mathrm{Al}$ & $11 \% \mathrm{Al}_{2} \mathrm{O}_{3}$ & $45 \% \mathrm{Al}_{2} \mathrm{O}_{3}$ & $58 \% \mathrm{Al}_{2} \mathrm{O}_{3}$ & $83 \% \mathrm{Al}_{2} \mathrm{O}_{3}$ & $\%$ measured \\
\hline & $6 \% \mathrm{Al}$ & $14 \% \mathrm{Al}$ & $7 \% \mathrm{Al}$ & $2 \% \mathrm{Na}$ & $\%$ measured \\
\hline $93 \% \mathrm{Ni}$ & $1 \% \mathrm{ZrO}_{2}$ & $6 \% \mathrm{ZrO}_{2}$ & $5 \% \mathrm{ZrO}_{2}$ & $15 \% \mathrm{ZrO}_{2}$ & $\%$ measured \\
\hline 250 & $81 \% \mathrm{Ni}$ & $35 \% \mathrm{Ni}$ & $30 \% \mathrm{Ni}$ & & 610 \\
\hline
\end{tabular}

In our case, the heating up and cooling down plasma technology shortened this time up to several seconds.

The above mentioned technology has been applied to increase the micro-hardness of tile.

\section{Test Results}

First evidence which confirmed significant increasing the micro hardness of tiles were crystal microstructure shown below at Figs. (14-16).

The micro-hardness test was conducted according to the standard ASTM E 384 by Vickers Indenter under load 200 gram and was measured in the metallographic cross section of the samples.

The experimental results of micro-hardness test are summarized in the following Table $\mathbf{5}$.

Table 5. Nano-Plasma Technology Results Show for MicroHardness

\begin{tabular}{|c|c|c|}
\hline Sample No. & Test Location & Hardness, HV \\
\hline \hline 1 & Core & $1920,2000,2080$ \\
\hline 2. & Bottom & 1990,2250 \\
\hline & Core & $1880,1910,2300$ \\
\hline 3. & Top & $1870,1890,1930$ \\
\hline & Bottom & $990,1000,1070,1090$ \\
\hline & Core & $2200,2450,2500$ \\
\hline & Top & $1950,2100,2130$ \\
\hline
\end{tabular}

\section{Morphology}

Polished and fracture surface were examined by SEM.

Typical polished surface are given at Figs. (14-16).

The alumina is well sintered and dense (Fig. 15).

In the same specimen, on the other hand, a partially sintered area with loose particles is seen (Fig. 16).

\section{Composition}

EDS analysis of the fracture surface indicates that aluminum oxide is reasonably pure. On the polished surfaces, small amounts of $\mathrm{Ca} \& \mathrm{Si}$ were detected, especially in the pores, possibly due to polishing residues.

\section{Density}

The average density of sample \# 3 was measured by the Archimedes method.

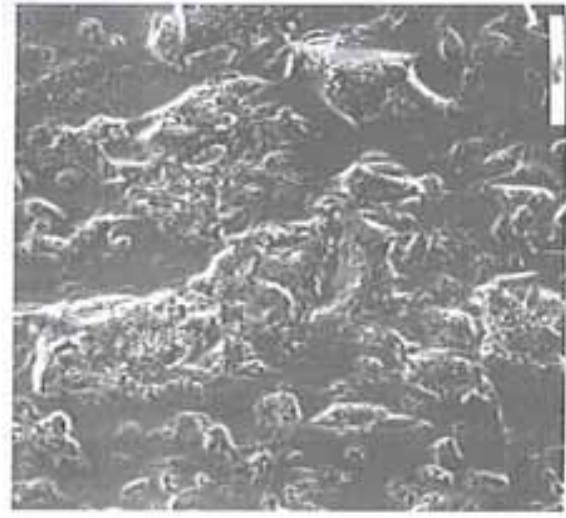

Fig. (14). Typical polished surface shown for sample \# 1, x500.

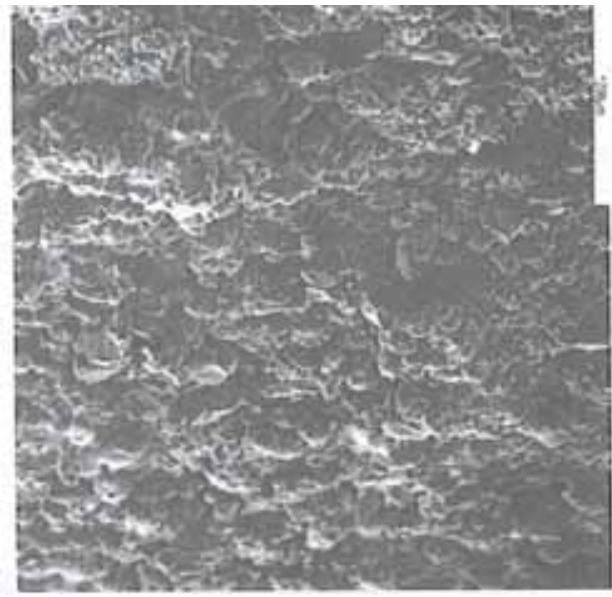

Fig. (15). Fracture surface of sample \# 3 shown for partially sintered area. X500.

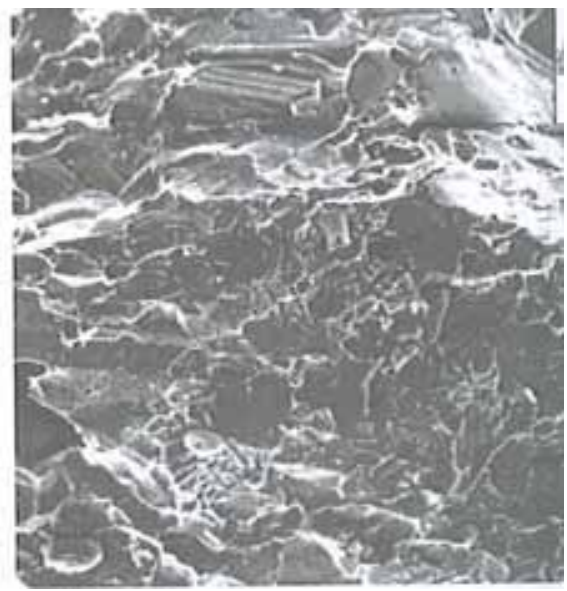

Fig. (16). Fracture surface shown for sample \# 3. X500. 
The density was $3.87 \mathrm{~g} / \mathrm{cm}^{3}$ which are $\sim 98 \%$ of theoretical density, with $1.7 \%$ open porosity.

\section{CONCLUSIONS}

The combination of several processes like Nano particles generation by shock waves, amorphous particles formations and quenching the melt flux with speed $10^{5}-10^{6} \mathrm{~K} / \mathrm{s}$ give rise to produce a tile with upper hardness characteristic for given material.

These results show the possibility of increasing the micro-hardness of alumina layers $(2,500 \mathrm{HV})$ within 1,000 HV in comparison with the regular sintering method.

These results create a new technological direction and allow us to reach superior micro-hardness especially necessary for military applications.

\section{REFERENCES}

[1] Gutman GB. Plasma spraying arc current modulation method. US Patent no 5900 272, May 4, 1999.

[2] Gutman B. Method and devices for plasma spraying and plasma cutting. Israel patent no $103069,1995$.

[3] Gutman B. Pulsed plasma and laser technologies and their business aspects. Cambridge International Science Publishing, London, 2000; p. 203.

[4] Gutman BB. Shock wave atomization: physical mechanisms of a modulated DC plasma torch during spray coating. Atomization Spray 2006; 16: 279-98.

[5] Viechnicki DJ, Kilman ML. Development and current status of armor ceramics. Ceramic Bull 1991; 70(6): pp.1035-9.

[6] Medvedovski E. Alumina Ceramics for Ballistic Protection. Am Ceram Soc Bull 2002; 81(3-4): 27-32, 45-50.

Received: March 30, 2009

Revised: April 6, 2009

Accepted: April 7, 2009

(c) Baruch B. Gutman; Licensee Bentham Open.

This is an open access article licensed under the terms of the Creative Commons Attribution Non-Commercial License (http://creativecommons.org/licenses/by$\mathrm{nc} / 3.0 /$ ) which permits unrestricted, non-commercial use, distribution and reproduction in any medium, provided the work is properly cited. 